\title{
An Intercomparison Study of the Germanium Isotope Composition of Geological Reference Materials
}

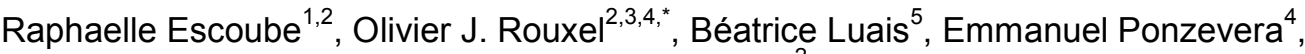 \\ Olivier F.X. Donard ${ }^{2}$
}

${ }^{1}$ LCABIE, U. Pau et Pays de l'Adour, CNRS UMR 525, Hélioparc 64053 Pau, France

2 UEB-UBO, European Institute for Marine Studies IUEM, 29280 Plouzané, France

3 Marine Chemistry and Geochemistry Department, Woods Hole Oceanographic Institution, Woods Hole, MA 02543, USA

${ }^{4}$ IFREMER, Centre de Brest, DRO/GM, 29280 Plouzané, France

${ }^{5}$ Centre de Recherches Pétrographiques et Géochimiques (CRPG) CNRS - UPR 2300, Nancy-Université, 15 rue

Notre Dame des Pauvres, BP 20, 54501 Vandoeuvre-lès-Nancy Cedex, France

*: Corresponding author : Olivier J. Rouxel, email address : orouxel@ifremer.fr

\begin{abstract}
:
Recent analytical developments in germanium stable isotope determination by multicollector ICP-MS have provided new perspectives for the use of $\mathrm{Ge}$ isotopes as geochemical tracers. Here, we report the germanium isotope composition of the NIST SRM 3120a elemental reference solution that has been calibrated relative to internal isotopic standard solutions used in the previous studies. We also intercalibrate several geological reference materials as well as geological and meteoritic samples using different techniques, including online hydride generation and a spray chamber for sample introduction to MC-ICP-MS, and different approaches for mass bias corrections such as sample-calibrator bracketing, external mass bias correction using $\mathrm{Ga}$ isotopes and double-spike normalisation. All methods yielded relatively similar precisions at around $0.1 \% 0(2 s)$ for $\delta^{74 / 70} \mathrm{Ge}$ values. Using igneous and mantle-derived rocks, the bulk silicate Earth (BSE) $\delta^{74 / 70} \mathrm{Ge}$ value was re-evaluated to be $0.59 \pm 0.18 \%$ o $(2 s)$ relative to NIST SRM 3120a. Several sulfide samples were also analysed and yielded very negative values, down to $-4.3 \%$, consistent with recent theoretical study of $\mathrm{Ge}$ isotope fractionation. The strong heavy isotope depletion in ore deposits also contrasts with the generally positive Ge isotope values found in many modern and ancient marine sediments.
\end{abstract}

\section{Résumé :}

De récents développements analytiques ont permit la détermination de la composition isotopique du germanium par ICP-MS multi-collecteur, permettant de nouvelles perspectives dans l'utilisation des isotopes du germanium en tant que traceur géochimique. Dans ce papier, la composition isotopique du germanium de la solution de réference élémentaire NIST SRM 3120a a été calibrée par rapport aux standards utilisés dans les précédentes études. Différents matériaux de références ont été aussi intercalibrés ainsi que des échantillons géologiques et météoritiques en utilisant différentes techniques tels que l'introduction par génération d'hydrure en ligne et par chambre cyclonique, mais aussi différentes approches de correction de biais de masse tels que l'encadrement " échantillon-standard », l'utilisation d'un standard externe avec l'introduction de Ga et la normalisation par double spike. Toutes ces méthodes présentent des précisions relativement similaires autour de $0.1 \%$ ( $2 s)$ pour la mesure du $\delta^{74 / 70} \mathrm{Ge}$. A partir des roches ingnées et dérivées du manteau, la valeur de $\delta^{74 / 70} \mathrm{Ge}$ de la terre silicatée globale (BSE) a été réévaluée autour de $0.59 \pm 0.18 \%$ (2s) par rapport au NIST SRM 3120a. Plusieurs échantillons de sulfures ont aussi été analysés et présentent des valeurs très négatives, jusqu'à-4.3\%, ce qui est consistant avec la récente étude théorique sur les fractionnements isotopiques du germanium. De plus, ce fort appauvrissement en isotope lourds dans les dépôts sulfurés contraste avec la tendance positive de la composition isotopique du germanium observée dans les sédiments marins actuels et passé.

Keywords : germanium ; Isotope ; Intercalibration ; reference materials

Mots clés : germanium ; Isotope ; Intercalibration ; materiaux de référence 
47

48

49

50

51

52

53

54

55

56

57

58

59

60

61

62

63

64

65

66

67

68

69

70

71

72

73

74

75

\section{Introduction}

Germanium (Ge) has 5 natural isotopes: ${ }^{70} \mathrm{Ge},{ }^{72} \mathrm{Ge},{ }^{73} \mathrm{Ge},{ }^{74} \mathrm{Ge}$ and ${ }^{76} \mathrm{Ge}$ with average relative isotope abundances of $20.84,27.54,7.73,36.28$ and $7.61 \%$, respectively. Early investigations of Ge isotopes using thermal ionization mass spectrometry (TIMS), SIMS and MC-ICP-MS were limited by an uncertainty of several per mil (Green et al. 1986, Hirata 1997, Shima 1964), mainly due to the presence of Ar-based interferences $\left(\mathrm{Ar}_{2}{ }^{+}\right.$and $\left.\mathrm{ArO}_{2}{ }^{+}\right)$at $\mathrm{m} / \mathrm{z} 72,74,76$, as well as interferences from ${ }^{70} \mathrm{Zn}$ and ${ }^{76} \mathrm{Se}$. More recently, further analytical developments by MC-ICP-MS have permitted high precision Ge-isotope measurement with repeatability around $0.06 \%$ per mass unit (Galy et al. 2003, Luais 2003, 2007, Rouxel et al. 2006, Siebert et al. 2006, Yang and Meija 2010). Notably, Rouxel et al. (2006) and Siebert et al. (2006) applied a hydride generation (HG) technique coupled to MC-ICP-MS, which allow high-precision Ge-isotope analyses on natural samples for Ge amounts down to 15 ng.

The analyses of Siebert et al. (2006) were done using a double spike approach while Rouxel et al. (2006) measured isotopic ratios and corrected for instrument fractionation with bracketing standards. In contrast, Luais et al. (2000) and Luais (2003, 2007) used a hexapolecollision cell MC-ICP-MS (Isoprobe GV Instrument) with $\mathrm{H}_{2}$ gas to remove $\mathrm{Ar}_{2}$ interferences, and corrected for instrument fractionation by using both Ga-isotopes as an internal normalization standard and by bracketing standards. Despite the obvious success in obtaining high precision measurement of Ge isotopes by MC-ICP-MS in a range of terrestrial and meteoritic materials, those previous studies have used a large diversity of techniques, standards, normalization ratios and instrumentations which preclude a straightforward comparison of published values. Thus, the concept of metrological traceability has not been applied.

Rouxel et al. (2006) obtained a crude estimate of the Ge isotopic composition of the Bulk Silicate Earth (BSE) by the analysis of various igneous rocks such as tholeiitic glasses from mid-ocean ridges, continental basalts and volcanic island basalts. Deep sea clays have $\delta^{74} \mathrm{Ge}$ values similar to BSE while modern deep-sea sponges and glauconite have $\delta^{74} \mathrm{Ge}$ values heavier than BSE. Considering that Ge isotope fractionation during biogenic opal and glauconite may favour enrichment in light isotopes in the forming product, it has been suggested that the Ge isotopic composition of the ocean is enriched in heavy isotopes relative to BSE (Rouxel et al. 2006). In addition, Mantoura (2006) carried out laboratory experiments indicating that cultured diatoms do not fractionate Ge isotopes. Luais (2003, 2007) 
81 demonstrated that iron meteorites have a $\delta^{74} \mathrm{Ge}$ values heavier than terrestrial samples. The homogeneous $\delta^{74} \mathrm{Ge}$ values for magmatic iron meteorites, regardless of their oxidation state suggests, in agreement with experimental data (Luais et al., 2009), that core formation processes do not fractionate significantly Ge isotopes in the metal phase with respect to the primitive material, providing an estimate for Ge isotopic composition of the solar nebula.

Siebert et al. (2006) reported Ge isotope composition of hydrothermal waters collected in the Oregon Cascades and in marine settings and found lighter isotope signatures relative to basalts. However, a preliminary intercomparison performed by the authors and colleagues suggests that the reported Ge-isotope compositions are plagued by calculating errors during the data reduction scheme (C. Siebert, personal communication), precluding further comparison with our study.

The aim of this paper is to compare analytical techniques to obtain Ge-isotope composition of selected geological reference materials and to intercalibrate Ge-isotope standards relative to the BSE estimate. We propose the use of a new reference material NIST3120a to report natural Ge-isotope variations. This approach, together with further studies of experimental and theoretical fractionation of Ge-isotopes (Galy et al. 2003, Luais et al., 2009, Li et al. 2009, Li and Liu 2010) are essential steps toward the development of Geisotopes as new geochemical tracer.

\section{Experimental procedures}

\section{Reagents and Germanium standard solutions}

103 The hydride generation reagent is composed of $10 \mathrm{~g}$ of sodium borohydride powder 104 (high purity $\mathrm{NaBH}_{4}$, Fisher Chemical) and $5 \mathrm{~g}$ of sodium hydroxide pellets (analytical grade $105 \mathrm{NaOH}$, Acros Organics) dissolved into 11 of ultra pure water (Milli-Q 18.2M $2 . \mathrm{cm}$, 106 Millipore), and is freshly prepared before each analytical session. During chemical 107 dissolution and purification, we used high purity $\mathrm{HNO}_{3}$ (distilled grade, CleanAcid, Analab) 108 and HF (optima grade, Fisher Chemical). Germanium standards used in this study include

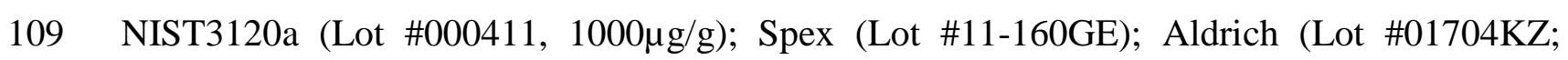
110 Luais, 2000, Luais 2007), JMC (Johnson Mattey, Karlsruhe, Lot \# 301230S; Luais 2007) and 111 Aristar (Lot \# used in Rouxel et al., 2006 - incorrectly reported as Aldrich standard solution). 112 We also used Ga (Spex; Lot \#12-98Ga; Cat \# PLGA2-2Y) and Ga international isotopic 113 standard (NBS - SRM994, Lot\# 680205, Luais et al., 2000; Luais 2007) prepared from Ga

114 metal as internal standards for instrumental mass bias corrections. Double Spike was prepared 
115 from Ge metal spikes 73-70 from Isoflex USA Company (Ge-70 \#32-01-70-3259 and Ge-73 116 \#32-01-73-1405). Each spike was dissolved separately in a mixture $\mathrm{HNO}_{3}$, sulfuric acid and 117 trace $\mathrm{HF}$ and mixed to obtain a ${ }^{73} \mathrm{Ge} /{ }^{70} \mathrm{Ge}$ ratio of $\sim 0.6$.

Geological reference materials and other geological samples

Several geological reference materials have been analyzed in this study for intercomparison purposes with previous studies by Rouxel et al. (2006). They include USGS standards (Govindaraju 1994) BHVO-2 (Hawaiian basalt), BIR-1 (Icelandic basalt), BCR-1 (Basalt, Columbia River Group USA), G-2 (Granite, Rhode Island USA), GH (Granite, Hoggar, Algeria), DNC-1 (Braggtown Dolerite, North Carolina, USA), DTS-1 (Dunite, Hamilton, Washington), PCC-1 (Peridotite- a partially serpentinized harzburgite, California USA), AN-G (Anorthosite, Fiskenaesset, Western Greenland), GLO (Glauconite, Normandy France), and IF-G (Iron Formation, West Greenland).

We also analyzed the Iron meteorite Odessa (IAB group) for which Ge-isotope composition has been previously reported by Luais (2003, 2007). We also report Ge-isotope composition of hydrothermal sulfides (sphalerite) from volcanogenic sulfide deposits, the 133 Navan $\mathrm{Zn}+\mathrm{Pb}$ ore deposit in Ireland (Blakeman et al., 2002), from continental hydrothermal $\mathrm{ZnS}$ ores from the St Salvy deposit in France (Luais, 2003, 2007), and from modern seafloor hydrothermal systems, the Lucky Strike field (Rouxel et al. 2004).

\section{Sample dissolution and chromatographic separation}

A procedure adapted from Rouxel et al. (2006), Luais (2007) and Luais (submitted) was applied in this study for Ge purification from siliceous matrices, iron meteorites and sulfides. For HG-MC-ICP-MS method (IFREMER and WHOI laboratories), about $50 \mathrm{mg}$ of siliceous material was dissolved in $\sim 3 \mathrm{ml}$ of $10 \mathrm{~mol} / \mathrm{l} \mathrm{HF}$ in a closed Teflon beaker on a hot plate at $70{ }^{\circ} \mathrm{C}$ and left to equilibrate overnight with an appropriate addition of double spike (spike/natural ratio 1). After appropriate dilution to $1 \mathrm{~mol} / \mathrm{l} \mathrm{HF}$ with ultrapure water, the solution was directly purified without evaporation through a chromatographic column containing $2 \mathrm{~mL}$ of anion exchange resin (AG1-X8 Resin; 100-200 mesh; Chloride Form; Cat \# 140-1441). The column is cleaned with several washes of $5 \mathrm{ml}$ of $0.28 \mathrm{~mol} / \mathrm{HNO}_{3}$, distilled $3 \mathrm{~mol} / \mathrm{L} \mathrm{HNO}_{3}$, and ultrapure water. After conditioning with $5 \mathrm{ml}$ of $1 \mathrm{~mol} / \mathrm{l} \mathrm{HF}$, the sample was loaded on the column and germanium strongly adsorbed on the resin. Matrix elements such $\mathrm{Ca}, \mathrm{Fe}, \mathrm{Si}$ or $\mathrm{Zn}$ were eluted and the resin further cleaned with $5 \mathrm{ml}$ of $1 \mathrm{~mol} / \mathrm{l} \mathrm{HF}$ followed by $3 \mathrm{ml}$ of ultrapure water. Ge was then eluted with $10 \mathrm{ml}$ of $3 \mathrm{~mol} / 1 \mathrm{HNO}_{3}$ and the 
149 solution evaporated slowly to dryness on a hot plate. The final residue was dissolved in $3 \mathrm{ml}$ 150 of $0.28 \mathrm{~mol} / 1 \mathrm{HNO}_{3}$ and ready for isotope analysis. Since the $\mathrm{HG}$ sample introduction system 151 allow complete separation of volatile Ge hydride from the aqueous sample matrix (e.g. 152 Rouxel et al., 2006), no further purification using cation exchange resin is required. 153 Procedures for iron meteorite and sulfide dissolution are detailed in Luais et al. (2000) and 154 Luais (2007). Briefly, it consists of dissolution using $2 \mathrm{~mol} / \mathrm{l}$ and $14 \mathrm{~mol} / \mathrm{l} \mathrm{HNO}_{3}$, 155 respectively, followed by Ge isolation using AG50X8 cation exchange resin with $0.5 \mathrm{~mol} / \mathrm{l}$ $156 \mathrm{HNO}_{3}$. Procedures for silicate matrices used at CRPG (Luais, submitted) consist of $\mathrm{HNO}_{3}+$ 157 HF dissolution followed by several steps of HF leaching to isolate Ge ( \pm matrix) in the 158 supernatant. After evaporation and subsequent dissolution in $1 \mathrm{~mol} / \mathrm{l} \mathrm{HF}$, an aliquot of the 159 sample is loaded on a AG1X8 anion exchange resin. Most of the remaining matrix is eluted 160 with $1 \mathrm{~mol} / \mathrm{l} \mathrm{HF}$, and Ge is subsequently collected using $0.2 \mathrm{~mol} / \mathrm{HNO}_{3}$. Purification of Ge is 161 then performed on AG50X8 cationic resin similarly developed for iron meteorite matrix. The 162 efficiency of these procedures including $100 \%$ yield and no isotopic fractionation during all 163 steps of Ge chemistry is demonstrated by Ge isotopic measurements of various matrices 164 doped with Ge standard, as well as Ge standard solutions after column separation. Details are 165 given in Luais (2007) for iron meteorite matrix and in Luais (submitted) and Rouxel et al. 166 (2006) for various silicate matrices from ultra-mafic, mafic to granitic in composition. In all 167 cases, the Ge isotopic composition of these Ge-dopped matrices is similar within error to the 168 measured Ge standard solution. 169

MC-ICP-MS isotope ratio measurements:

171 Germanium isotopes ratios were determined with a Thermo Neptune (Thermo Fisher 172 Scientific; Waltham, MA, USA) at the Pôle Spectrométrie Océan (PSO, Brest) at IFREMER 173 (Plouzané, France) and WHOI (Woods Hole, USA) using the hydride generation technique 174 described by Rouxel et al. (2006). Pure standard solution and purified sample measurements 175 were also performed on a Nu Plasma MC-ICP-MS at LCABIE laboratory (Pau, France) and 176 Isoprobe (GV) MC-ICP-MS at CRPG laboratory (Nancy, France) (Luais 2007). The Neptune 177 at WHOI and IFREMER was operating at low-mass resolution mode and ${ }^{70} \mathrm{Ge},{ }^{72} \mathrm{Ge},{ }^{73} \mathrm{Ge}$ 178 and ${ }^{74} \mathrm{Ge}$ were measured on $\mathrm{L} 2, \mathrm{C}, \mathrm{H} 1$, and $\mathrm{H} 2$ cups while ${ }^{68} \mathrm{Zn},{ }^{69} \mathrm{Ga},{ }^{71} \mathrm{Ga}$ and ${ }^{77}$ Se were also 179 monitored on L4, L3, L1 and H4 cups. The isotope ${ }^{76} \mathrm{Ge}$ was not measured due to a major 180 interference of ${ }^{38} \mathrm{Ar}_{2}$. For the $\mathrm{Nu}$ plasma measurements at LCABIE, we set the cups as H6, $181 \mathrm{H} 4, \mathrm{H} 2$, and L2 for 74, 73, 72 and 70 at low mass resolution and the Ax and L3 cups for 71 182 and $69 \mathrm{Ga}$ isotopes. For the GV Isoprobe measurements (CRPG), ${ }^{70} \mathrm{Ge},{ }^{72} \mathrm{Ge},{ }^{73} \mathrm{Ge}$ and ${ }^{74} \mathrm{Ge}$ 
183 were measured on $\mathrm{Ax}, \mathrm{H} 2, \mathrm{H} 3$ and $\mathrm{H} 4$ cups while ${ }^{68} \mathrm{Zn},{ }^{69} \mathrm{Ga}$, and ${ }^{71} \mathrm{Ga}$ were measured on L3, 184 L2, and H1 cups.

185 Several introduction systems were used and include: (1) a cyclonic spray chamber 186 (SiS) equipped with PTFE micro concentric nebuliser at $50 \mu \mathrm{l} / \mathrm{min}$ for WHOI, IFREMER and 187 CRPG (Luais 2007) while a Quartz micro concentric nebuliser at $100 \mu \mathrm{l} / \mathrm{min}$ was used for 188 LCABIE measurements; (2) continuous flow hydride generation systems, CETAC HGX-200 189 at WHOI and IFREMER (see Rouxel et al., 2006 for instrument settings) and a custom-built 190 HG generator at the LCABIE.

191 Instrumental mass bias was corrected using several techniques as described in 192 previous studies (Galy et al. 2003, Luais 2007, Rouxel et al. 2006, Siebert et al. 2006): (1) a 193 sample-standard bracketing (referred to as SSB) technique that involves the measurement of 194 the Ge standard solution, before and after each unknown sample (Galy et al. 2003, Rouxel et 195 al. 2006); (2) external normalization to Ga-isotopes (referred as Ga-Cor) (Galy et al. 2003, 196 Hirata 1997, Luais et al. 2000, Luais 2007, Siebert et al. 2006) and Cu-isotopes. (3) Double 197 spike (DS) correction (73/70) was performed as described by Siebert et al. (2006). The double 198 spike solution was mixed with the sample before chemical purification with a spike/natural 199 ratio of around $1(\mathrm{~g} / \mathrm{g})$. Data reduction of Ge-isotope ratios was performed using a scheme 200 similar to Siebert et al. (2001). In some cases, we coupled the hydride generation system with 201 the regular cyclonic spray chamber using an extra inlet available on the spray chamber. This 202 approach allowed a direct comparison of instrumental mass bias induced by both techniques 203 and the calculation of hydride generation yield. It also permitted the use of Ga as an internal 204 standard to correct for instrumental mass bias during hydride generation. 205 206

\section{Results and discussion} 207

\section{Notation and data normalization}

209 Germanium isotope composition can be reported using several possible notations, such as: 210

$$
\delta^{x} G e(\%)=\left(\frac{\left({ }^{x} G e /^{70} G e\right)_{\text {sample }}}{\left({ }^{x} G e /^{70} G e\right)_{S T D}}-1\right) \times 1000
$$

Where $\mathrm{x}=74,73$ or 72 and STD corresponds to the normalization to Ge-standard. 214 Currently, there is no consensus in the way to report Ge-isotope ratios. Siebert et al. (2006) 
215 reported $\delta^{74 / 72} \mathrm{Ge}$ due to the double spike correction using ${ }^{73} \mathrm{Ge}$ and ${ }^{70} \mathrm{Ge}$ spikes. Galy et al. 216 (2003) reported $\delta$ Ge per mass unit while Rouxel et al. (2006) and Luais $(2003,2007)$ reported $217 \delta^{74 / 70} \mathrm{Ge}$ (together with other 73/70 and 72/70 isotope ratios). Due to larger abundances and 218 minor isobaric interferences, the ${ }^{74} \mathrm{Ge} /{ }^{70} \mathrm{Ge}$ ratio seems to be optimum for reporting $\mathrm{Ge}$ 219 isotopes. Throughout this study, we reported $\delta^{74} \mathrm{Ge} /{ }^{70} \mathrm{Ge}$ values relative to SRM3120a which 220 is a concentration standard produced in large amount.

\section{Isobaric interferences and instrumental mass bias}

Ge isotope measurements suffer from molecular interferences, such as ${ }^{35} \mathrm{Cl}^{35} \mathrm{Cl}^{+}$on ${ }^{70} \mathrm{Ge}^{+} ;{ }^{40} \mathrm{Ar}^{16} \mathrm{O}_{2}{ }^{+}$and ${ }^{36} \mathrm{Ar}^{36} \mathrm{Ar}^{+}$on ${ }^{+72} \mathrm{Ge}^{+},{ }^{58} \mathrm{Ni}^{16} \mathrm{O}^{+}$and ${ }^{38} \mathrm{Ar}^{36} \mathrm{Ar}^{+}$on ${ }^{74} \mathrm{Ge}^{+}$and ${ }^{38} \mathrm{Ar}^{38} \mathrm{Ar}^{+}$and ${ }^{36} \mathrm{Ar}^{40} \mathrm{Ar}^{+}$on ${ }^{76} \mathrm{Ge}^{+}$. On the Neptune and Nu Plasma coupled to $\mathrm{HG}$, those interferences are minimized and are generally negligible except for ${ }^{76} \mathrm{Ge}$, as previously discussed by Rouxel et al. (2006). We however observed a ubiquitous interference on ${ }^{70} \mathrm{Ge}^{+}$during the early stage of analytical development on the Neptune, probably from ${ }^{40} \mathrm{Ar}^{14} \mathrm{~N}^{16} \mathrm{O}$ due to the use of $\mathrm{X}$-cones which may induce a higher oxide-level. Therefore, we only used normal cones throughout this study. On the GV Isoprobe, hydrogen addition in the hexapole collision cell was used to remove $\mathrm{Ar}_{2}$ interferences (Luais et al. 2000; Luais, 2007).

Ge-isotope measurements, and in particular double-spike correction, may suffer from 233 potential $\mathrm{GeH}^{+}$interference. Therefore, we evaluated the contribution of ${ }^{70} \mathrm{GeH}^{+}$on mass 71 234 by measuring $\left({ }^{71} \mathrm{Ga}^{+}+{ }^{70} \mathrm{GeH}^{+}\right) /{ }^{69} \mathrm{Ga}^{+}$ratios. This approach permits us to evaluate the influence 235 of $\mathrm{GeH}^{+}$on the signal, which is around $0.001 \%$ and thus negligeable, in agreement with 236 Luais et al. (2000).

Isotopic measurements on all instruments were also corrected for $\mathrm{Zn}$ interferences on 238 mass 70 using ${ }^{68} \mathrm{Zn}$, with a mass bias applied on ${ }^{70} \mathrm{Zn} /{ }^{68} \mathrm{Zn}$ ratios (Luais, 2007).

As germane $\left(\mathrm{GeH}_{4}\right)$ formation in the hydride generator may induce isotope fractionation, we coupled the spray injection system with the HG to evaluate potential mass bias. This analytical setup allowed a direct comparison of the Ge-isotope ratios of the standard introduced using conventional spray chamber ("Standard") vs. hydride generation ("Sample") (Figure 1). The SRM3120a Ge standard solution was adjusted to a concentration 244 of $250 \mathrm{ng} / \mathrm{g}$ for spray chamber injection and to $10 \mathrm{ng} / \mathrm{g}$ for hydride generation to reach similar 245 intensity for both introduction systems. The results suggest that the difference in mass bias 246 between the spray chamber and the HG system is about $0.05+/-0.07 \%$ (2s) per mass unit, 247 which suggest that, either Ge-hydride formation does not fractionate Ge-isotopes or that the 248 hydride formation yield is quantitative. Considering that the spray chamber system has an 
249 efficiency of Ge transfer into the plasma torch of about $20 \%$ (determined using the volume of 250 solution taken vs. solution drained in waste), we can determine an overall sensitivity in 251 abundance of $0.85 \mathrm{pg} / \mathrm{V}$. In comparison, we calculate that hydride generation has a sensitivity 252 of $0.91 \mathrm{pg} / \mathrm{V}$ which suggest that about $100 \%$ of germanic acid in solution is reduced to 253 germane species.

\section{Assessment of standard and double-spike isotope composition}

While Ga is traditionally used to control the mass bias for Ge analyses (Galy et al. 257 2003, Hirata 1997, Luais et al. 2000, Luais 2007,), we recognize that such approach may not 258 allow absolute Ge isotope ratio measurement since instrumental mass bias may be different 259 between elements (e.g. Maréchal et al. 1999, Yang and Meija 2010, Meija et al. 2009). We 260 however found that $\mathrm{Ga}$ or $\mathrm{Cu}$ can be appropriate elements for external mass bias correction 261 and determination of relative isotopic composition (in delta value) of Ge standards or 262 samples. The assumption of identical mass bias for analyte and standard however require 263 identical matrix composition and concentrations. In addition, external mass bias correction 264 yields identical results in delta values than standard-sample bracketing method or double 265 spike normalization, as presented in Tables 2 and 3 and discussed below.

The double-spike composition was defined relative to the NIST 3120a composition 267 obtained on the Neptune at PSO, Brest (Table 1) using conventional spray chamber 268 introduction system. In order to calibrate the Ge-isotope ratios of NIST 3120a, we used a 269 Gallium standard solution (Spex; Lot \#12-98Ga) to correct for instrumental mass bias using $270{ }^{69} \mathrm{Ga} /{ }^{71} \mathrm{Ga}$ ratio of 1.50676 (Machlan et al., 1986). This approach was also used to monitor 271 instrumental mass bias between analyses of pure standard and double spike. It is important to 272 note that both our double spike and NIST 3120a calibration reported in Table 1 may differ 273 from the true value but this potential bias does not affect the final isotope ratios when using 274 the delta notation. Although we didn't determine the optimum double spike composition or 275 spike/natural ratios using error propagation tests, Figure 2 shows that spike/natural ratio 276 between 0.8 to 3.5 yield consistent results with overall precision of $0.15 \%$ ( $2 \mathrm{~s}$ ). In practice, a 277 ratio between 1 to 2 was routinely used for isotope analysis. This optimal ratio is very similar 278 to the one used by Siebert et al (2006).

\section{Intercomparison of Ge isotope compositions of Ge standard solutions}

281 The average compositions of NIST3120a and other standard solutions over multiple 282 analytical sessions for different instruments and measurement setups are reported in Table 2. 
283 Aristar and Spex solutions show an enrichment in the light isotope of approximately the same 284 proportion $\left(\delta^{74 / 70} \mathrm{Ge}=-0.64+/-0.18 \%\right.$ (2s) and $-0.71+/-0.20 \%$ (2s), respectively). JMC 285 standard also presents an enrichment in the light isotope although in smaller proportion, with 286 a $\delta^{74 / 70} \mathrm{Ge}$ value of $-0.32+/-0.10 \%$ (2s). The Aldrich standard shows the lightest $\delta^{74 / 70} \mathrm{Ge}$ 287 values at $-2.01+/-0.22 \%$ (2s). Several sample introduction systems were tested, using either 288 spray chamber ( $\mathrm{SiS}$ ) or hydride generation (HG) for different instruments (Neptune, $\mathrm{Nu}$ 289 plasma or Isoprobe) and no systematic differences were found. It is also important to note that 290 standard-sample bracketing, Ga normalization and double spike corrections yielded similar 291 results, both in terms of Ge isotope composition and analytical precision. 292

293 Ge isotope composition of geochemical RM and re-evaluation of the bulk silicate Earth value 294 Selected geochemical RM, measured using double spike (this study), sample-standard 295 bracketing (Rouxel et al. 2006), and Ga normalization (Luais 2007) methods are reported in 296 Table 3. In addition, we report precise Ge concentrations determined by isotope dilution since 297 the double spike data reduction scheme offers the advantage to also calculate precisely the Ge 298 concentration of the samples.

299 Based on these data, the bulk silicate Earth value has been re-evaluated as $\delta^{74 / 70} \mathrm{Ge}=$ $300 \quad 0.56 \%$ versus NIST SRM3120a. This average is determined from igneous rocks (BHVO-2; 301 BIR-1; BCR-1) having limited variations $(2 \mathrm{~s}=0.08 \%$ ). Granitic rocks display significant 302 deviation from the bulk silicate Earth with G-2 (Rhode Island, USA) having a slightly lighter 303 composition at $0.40+/-0.04 \%$ (2s). Ultramafic rocks, although less concentrated in Ge, 304 present similar compositions as basaltic rocks. We note that NIST3120a is the standard whose 305 isotope composition is the closest to the BSE relative to the other standard solutions used 306 previously (Table 2). As discussed below, iron formation IF-G and marine sediment GL-O 307 yield heavier $\delta^{74 / 70} \mathrm{Ge}$ values at $1.03+/-0.10 \%$ (2s) and $2.44+/-0.14 \%$ (2s) respectively.

308 Although Ge concentrations have been widely reported in geochemical reference 309 materials (Govindaraju 1994), they are only rarely analyzed by isotope dilution and even 310 more rarely by MC-ICP-MS after chemical purification. In most cases, our new concentration 311 data in Table 3 are within 5\% of previously reported data (e.g. BIR-1, BCR-1, G-2, DNC-1, 312 AN-G, IF-G) while differences may be up to 10-20\% in some cases (e.g. GH, DTS-1, PCC-1, 313 GL-O). 314

315 Ge isotope composition of meteorites, sediments and sulfide deposits 
As shown in Figure 3, the absolute range of $\delta^{74 / 70} \mathrm{Ge}$ values in rocks and minerals is about $8.05 \%$ which is comparable or even larger than most non traditional stable isotope systems (e.g. Anbar and Rouxel 2007). The strong heavy isotope depletion in sulfides contrasts strongly with the generally positive Ge isotope values found in many modern and ancient marine sediments (e.g. banded iron formations, glauconite).

Glauconite (GLO) and Iron Formation (IF-G) are two iron-rich rocks where redox conditions were important in their formation. Glauconite is a secondary clay mineral which is formed in marine sediments during the reduction of $\mathrm{Fe}(\mathrm{III})$ to $\mathrm{Fe}(\mathrm{II})$, while Archean Iron Formation is believed to have formed in globally anoxic oceans where hydrothermal Fe(II) was partially oxidized and co-precipitated with silica, either biotically or abiotically (e.g. Bekker et al., 2010). In both deposit types, Ge is enriched relative to crustal values with $\mathrm{Ge} / \mathrm{Si}$ ratios of $6.44 \times 10^{-6}$ and $2.7 \times 10^{-5} \mathrm{~mol} / \mathrm{mol}$ for Glauconite and Iron formation, respectively. Since Galy et al. (2002) and Li and Liu (2010) suggested that Ge adsorbed onto iron oxyhydroxide is enriched in light isotopes, the positive $\delta^{74 / 70} \mathrm{Ge}$ values for GLO and IF-G is best explained by the heavy isotope composition of their Ge sources. In this case, the slightly lighter values for IF-G may potentially result from the contribution of hydrothermal Ge to Archean oceans (Hamade et al. 2003). Further studies are however required to address this issue.

Deep sea sponges of the NE Pacific (Rouxel et al. 2006) show an average isotope composition at around $2.47 \%$. The relatively high $\delta^{74 / 70} \mathrm{Ge}$ values obtained for different species at different depths also suggest that sponges likely record the Ge isotope composition of seawater. This value is a lower bound of the Ge isotopic composition of modern seawater because, if sponges fractionate Ge isotopes, they likely discriminate against heavy isotopes as already observed for Si isotopes. More recently, Mantoura (2006) reported $\delta^{74 / 70} \mathrm{Ge}$ values for cleaned diatom opal from Holocene sediments at around $3.3 \%$. Those results, together with

341 the lack of $\mathrm{Ge}$ isotope fractionation observed during $\mathrm{Ge}$ uptake by cultured diatoms 342 (Mantoura, 2006), further confirm that seawater is enriched in the heavy Ge isotopes, 343 probably close to $3 \%$.

Two independent Ge isotope analyses of the non-magmatic iron meteorite Odessa are 345 reported in Table 4 and are in perfect agreement. Also is reported the recalculated Ge isotopic 346 composition of the magmatic iron meteorite Braunau (IIA). It is worthwhile to note that the 347 Ge isotope composition of various types of iron meteorites (magmatic and non-magmatic 348 irons) deviate from BSE in contrast to other heavy stable isotope systems (such as $\mathrm{Cu}, \mathrm{Zn}, \mathrm{Fe}$; 
349 Moynier et al. 2007), confirming the complexity of metal-silicate segregation and the 350 importance of volatilization/alteration effects (Luais, 2007).

351 Both sphalerite from ancient $\mathrm{Pb}-\mathrm{Zn}$ ore deposits (Blakeman et al. 2002) and seafloor 352 hydrothermal deposits at Lucky Strike (Rouxel et al. 2004) have been analyzed and an 353 average $\delta^{74} \mathrm{Ge}$ value of $-3.53 \pm 0.51 \%$ o has been obtained (Table 4). Sphalerite from the single $354 \mathrm{ZnS}$ ore deposit of St Salvy mine (France), precipitated from hydrothermal fluids related to 355 plutonic intrusion, also exhibit negative values with a range of -1 to $-2 \%$ (Luais, 2007). 356 These results are interesting because Ge isotopes in sulfides are completely shifted toward 357 negative values by $\sim 4 \%$ relative to BSE. In contrast, preliminary Ge isotope analysis from 358 hydrothermal fluids yield variable $\delta^{74} \mathrm{Ge}$ values around $1.9 \pm 0.5 \%$ (Escoube et al. 2008, 359 Rouxel et al. 2008). The recent study by Li et al. (2009) estimating equilibrium fractionation 360 factors in the Ge isotope system suggested a very large fractionation toward lighter values (up 361 to $10 \%$ at $25{ }^{\circ} \mathrm{C}$ ) in Ge-bearing sulfides relative to 4-coordinated Ge-O compounds (e.g. $362 \mathrm{Ge}(\mathrm{OH})_{4}(\mathrm{aq})$ or quartz). Therefore, the large difference between sulfides and BSE is best 363 explained by a strong isotopic fractionation (may be up to $4.5 \%$ ) during sulfide precipitation 364 in hydrothermal systems. 365

\section{Conclusion}

367 This study permits an intercomparison of germanium isotope measurement techniques 368 as well as a calibration of several geological reference materials and mono-elemental standard 369 solutions used in previous studies. Different methodologies were used during this study: (1) 370 introduction by on-line hydride generation and spray chamber, and (2) mass bias correction 371 by sample-standard bracketing, external mass bias correction using $\mathrm{Ga}$ or $\mathrm{Cu}$ isotopes and 372 double spike normalization. Even if all methods yield consistent isotope composition with 373 similar precisions (2s 0.15\% ), the double spike correction offers the advantage of providing 374 high-precision Ge concentrations and correcting for potential Ge isotope fractionation during 375 sample dissolution and purification.

376 Using igneous and mantle-derived rocks, the Bulk Silicate Earth (BSE) was re377 evaluated to $0.59+/-0.18 \%$ (2s) relative to NIST3120a. In comparison, Iron meteorites 378 exhibit more positive values of $\delta^{74 / 70} \mathrm{Ge}$ up to $+1.5 \%$. We report an overall $\delta^{74 / 70} \mathrm{Ge}$ variation 379 in terrestrial rocks and minerals of about $8 \%$. This range is comparable or even larger than 380 most non-traditional stable isotope systems (e.g., Fe). This large range of compositions is 381 mainly due to the extreme value (down to $-4.3 \%$ ) for sulfide samples originating from 
382 hydrothermal environments, consistent with theoretical calculations ( $\mathrm{Li}$ et al. 2009). This 383 strong isotope depletion in sulfides contrasts drastically with the generally positive Ge isotope 384 values found in many modern and ancient marine sediments (e.g. banded iron formations, 385 glauconite). Large variation in germanium stable isotopes and their reproducible measurement 386 provides new perspectives on the use of Ge as a novel geochemical tracer, in particular for 387 tracing planetary and oceanic processes.

\section{Acknowledgements}

391 This study was supported by the Woods Hole Oceanographic Institution, Europole 392 Mer, UEB, UBO, IFREMER and CRPG Nancy (INSU-PNP). Lary Ball (WHOI), Jurek 393 Blustajn (WHOI), Maureen Auro (WHOI), Yoan Germain (IFREMER), Sylvain Bérail 394 (LCABIE) and Delphine Yeghicheyan (SARM-CRPG-Nancy) are thanked for their technical 395 support. We thank Stefan Lalonde, Thomas Meisel and two anonymous reviewers for helpful 396 comments on the manuscript. Adrian Boyce and Yves Fouquet are thanked for providing 397 sulfide samples. 


\section{Figure Captions}

400

401 Figure 1: (A) Comparison between hydride generation (HG) and spray chamber (SiS) 402 methods for Ge isotope analysis. A NIST3120a solution was alternatively introduced though 403 the HG (square), considered as an "unknown sample" at a concentration of $10 \mathrm{ng} / \mathrm{g}$, and 404 through the SiS (Diamond), used as "bracketing standard" at a concentration of $250 \mathrm{ng} / \mathrm{g}$. The 405 concentrations were adjusted to obtain the same voltage (graph A). (B) Ge isotope 406 composition (in delta values) of the NIST3120a standard determined by HG and normalized 407 to SiS values.

408

409 Figure 2: Ge isotope composition of NIST3120a and Aldrich standards determined using a 410 double spike method with different Spike/Sample ratios. While the addition of spike in 411 proportions of 0.6-4 relative to sample yielded approximately stable $\delta^{74} \mathrm{Ge}$ values, analyses 412 are best performed with Spike/Sample ratios between 1 and 2.

413

414 Figure 3: Compilation of Ge isotope composition $\left(\delta^{74 / 70} \mathrm{Ge}\right)$ of geological reference materials 415 and natural samples versus NIST3120a; (a) Luais, 2007; (b) Rouxel et al., 2006; (c) this 416 study; (d) Mantoura (2006). 
1

2

3

4

5

7

8
419

420 Table 1: Ge isotope compositions of NIST3120a standard and Ge70-73 double spike 421 determined on the Neptune MC-ICP-MS after internal normalisation to Ga for instrumental 422 mass bias correction

423

424 Table 2: Intercalibration of Ge isotope composition of standard solutions against NIST 3120a. 425

426 Table 3: Intercomparison study of Ge isotope compositions of geochemical RM versus NIST 427 3120a.

428

429 Table 4: Ge isotope compositions of sulfides and iron meteorites. 
430

431

432

433

434

435

436

437

438

439

440

441

442

443

444

445

446

447

448

449

450

451

452

453

454

455

456

457

458

459

460

461

462

463

464

465

466

467

468

469

470

471

472

473

474

475

476

477

478

\section{$\underline{\text { References. }}$}

Anbar A.D. and Rouxel O. (2007)

Metal stable isotopes in paleoceanography. Annual Review of Earth and Planetary Sciences, 717-746.

Blakeman R.J., Ashton J.H., Boyce A.J., Fallick A.E. and Russell M.J. (2002)

Timing of interplay between hydrothermal and surface fluids in the Navan $\mathrm{Zn}+\mathrm{Pb}$ ore body, Ireland: Evidence from metal distribution trends, mineral textures, and $\mathrm{d} 34 \mathrm{~S}$ analyses Economic Geology, 97, 73-91.

Chang T.-L., Li W.-J., Qiao G.-S., Qian Q.-Y. and Chu Z.-Y. (1999)

Absolute isotopic composition and atomic weight of germanium International Journal of Mass Spectrometry, 189, 205-211.

Escoube R., Rouxel O. and Donard O.F.X. (2008)

Measurement of Germanium isotope composition in marine samples by hydride generation coupled to MC-ICP-MS. Geophysical Research, 10, abstract EGU2008-A-12035.

Galy A., Pokrovsky O.S. and Shott J. (2002)

Ge-isotope fractionation during its sorption on goethite: an experimental study Geochemica et Cosmochimica Acta, 66, A259.

Galy A., Pomiès C., Day J.A., Pokrovsky O.S. and Schott J. (2003)

High precision measurement of germanium isotope ratio variations by multiple collectorinductively coupled plasma mass spectrometry Journal of Analytical Atomic Spectrometry, 18, 115-119.

\section{Govindaraju K. (1994)}

compilation of working values and sample description for 383 geostandards Geostandards Newslett., 18, 1-158.

Green M.D., Rosman K.J.R. and De Laeter J.R. (1986)

The isotopic composition of germanium in terrestrial samples International Journal of Mass Spectrometry and Ion Processes, 68, 15-24.

Hamade T., Konhauser K.O., Raiswell R., Goldsmith S. and Morris R.C. (2003)

Using Ge/Si ratios to decouple iron and silica fluxes in Precambrian banded iron formations Geology, 31, 35-38.

Hirata T. (1997)

Isotopic variations of germanium in iron and stony iron meteorites Geochimica et Cosmochimica Acta, 61, 4439-4448.

Li X., Zhao H., Tang M. and Liu Y. (2009)

Theoretical prediction for several important equilibrium Ge isotope fractionation factors and geological implications Earth and Planetary Science Letters, 287, 1-11.

Li X.F. and Liu Y. (2010) 
479 First-principles study of $\mathrm{Ge}$ isotope fractionation during adsorption onto $\mathrm{Fe}(\mathrm{III})$ 480 oxyhydroxides surfaces Chemical Geology, 278, 15-22.

481

482

483

484

485

486

487

488

489

490

491

492

493

494

495

496

497

498

499

500

501

502

503

504

505

506

507

508

509

510

511

512

513

514

515

516

517

518

519

520

521

522

523

524

525

526

527

528

Luais B. (2007)

Isotopic fractionation of germanium in iron meteorites: Significance for nebular condensation, core formation and impact processes Earth and Planetary Science Letters, 262, 21-36.

Luais B., Framboisier X., Carignan J., and Ludden J. (2000) Analytical development of Ge isotopic analyses using multi-collection plasma source mass spectrometry: Isoprobe MCHex-ICP-MS (Micromass). Geoanalysis 2000, Pont-à-Mousson, France, 45-46.

Luais B. (2003). Germanium isotope systematics in Meteorites. Meteorit. Planet. Sci., 38, A31.

Luais B., Toplis M.J., Tissandier L., Roskosz M. (2009)

Metal-silicate segregation and fractionation of Ge isotopes : comparison with experimental

data and meteorites, Meteorit. Planet. Sci. 44, 7, A124.

Machlan, L.A., Gramlich, J.W., Powell, L.J., Lambert, G.M. (1986)

Absolute isotope abundance ratio and atomic weight of a reference sample of Gallium. J. Res. Natl. Bur. Stand. 91, 323-331.

Mantoura S. (2006)

Development and Application of Opal Based Paleoceanographic Proxies. PhD Thesis, University of Cambridge, 204 p.

Maréchal C.N., Télouk P. and Albarède F. (1999)

Precise analysis of copper and zinc isotopic compositions by plasma-source mass spectrometry Chemical Geology, 156, 251-273.

Meija J., Yang L., Sturgeon R., Mester Z. (2009)

Mass Bias Fractionation Laws for Multi-Collector ICPMS: Assumptions and Their Experimental Verification. Analytical Chemistry, 81, 6774-6778.

Moynier F., Blichert-Toft J., Telouk P., Luck J.M. and Albarède F. (2007)

Comparative stable isotope geochemistry of $\mathrm{Ni}, \mathrm{Cu}, \mathrm{Zn}$, and $\mathrm{Fe}$ in chondrites and iron meteorites Geochimica et Cosmochimica Acta, 71, 4365-4379.

Rosman K.J.R. and Taylor P.D.P. (1998)

Isotopic composition of the elements 1997 Pure \& Appl. Cherm, 70, pp. 217-235.

Rouxel O., Escoube R. and Donard O.F.X. (2008)

Measurement of Germanium isotope composition in marine samples by hydride generation coupled to MC-ICP-MS Geochim. Cosmochim. Acta, 72, (12S) A809.

Rouxel O., Fouquet Y. and Ludden J.N. (2004)

Subsurface processes at the Lucky Strike hydrothermal field, Mid-Atlantic Ridge; evidence from sulfur, selenium, and iron isotopes Geochimica et Cosmochimica Acta, 68, 2295-2311. 
530 Rouxel O., Galy A. and Elderfield H. (2006)

531 Germanium isotopic variations in igneous rocks and marine sediments Geochimica et 532 Cosmochimica Acta, 70, 3387-3400.

533

534

535

536

537

538

539

540

541

542

543

544

545

546

547

548

549

550

\section{Shima M. (1964)}

The distribution of germanium and tin in meteorites Geochimica et Cosmochimica Acta, 28, 517-532.

Siebert C., Nägler T.F. and Kramers J.D. (2001)

Determination of molybdenum isotope fractionation by double-spike multicollector inductively coupled plasma mass spectrometry Geochemistry, Geophysics, Geosystems, 2.

Siebert C., Ross A. and McManus J. (2006)

Germanium isotope measurements of high-temperature geothermal fluids using double-spike hydride generation MC-ICP-MS Geochimica et Cosmochimica Acta, 70, 3986-3995.

Yang L. and Meija J. (2010)

Resolving the germanium atomic weight disparity using multicollector ICPMS Analytical Chemistry, 82, 4188-4193. 
Table 1

\begin{tabular}{lcccccc}
\hline \multicolumn{1}{c}{ Name } & ${ }^{74} \mathrm{Ge} /{ }^{70} \mathrm{Ge}$ & 2s & ${ }^{73} \mathrm{Ge} /{ }^{70} \mathrm{Ge}$ & $2 \mathrm{~s}$ & ${ }^{72} \mathrm{Ge} /{ }^{70} \mathrm{Ge}$ & $2 \mathrm{~s}$ \\
\hline DS $\left({ }^{70} \mathrm{Ge} \cdot{ }^{73} \mathrm{Ge}\right)$ & 0.07614 & 0.00010 & 0.60707 & 0.00008 & 0.05626 & 0.00008 \\
NIST3120a & 1.76094 & 0.00005 & 0.37335 & 0.00003 & 1.32901 & 0.00004 \\
\hline
\end{tabular}


Table 2

\begin{tabular}{|c|c|c|c|c|c|c|c|c|c|c|c|}
\hline \multirow[t]{2}{*}{ Lab } & \multicolumn{2}{|c|}{ Method } & $\mathrm{nb \#}$ & $\delta^{74 / 70} \mathrm{Ge}$ & $2 s$ & $\delta^{73 / 70} \mathrm{Ge}$ & $2 s$ & $\delta^{72 / 70} \mathrm{Ge}$ & $2 s$ & $\delta^{74 / 72} \mathrm{Ge}$ & $2 s$ \\
\hline & & & & \multicolumn{2}{|l|}{ vs. NIST3120a } & \multicolumn{2}{|c|}{ vs. NIST3120a } & \multicolumn{2}{|c|}{ vs. NIST3120a } & \multicolumn{2}{|c|}{ vs. NIST3120a } \\
\hline \multicolumn{3}{|c|}{ "ARISTAR" standard } & & $\underline{-0.64}$ & $\underline{0.18}$ & $\underline{-0.54}$ & $\underline{0.18}$ & $\underline{-0.38}$ & $\underline{0.26}$ & $\underline{-0.28}$ & $\underline{0.03}$ \\
\hline \#1 & $\mathrm{HG}$ & SSB & 11 & -0.58 & $\overline{0.12}$ & $n d$ & & -0.30 & 0.09 & -0.28 & 0.04 \\
\hline$\# 1$ & $H G$ & $\mathrm{Ga}$ & 11 & -0.57 & 0.08 & nd & & -0.30 & 0.05 & -0.28 & 0.07 \\
\hline \#2 & SiS & SSB & 4 & -0.59 & 0.02 & -0.47 & 0.04 & -0.33 & 0.01 & -0.26 & 0.01 \\
\hline \#2 & SiS & DS & 4 & -0.61 & 0.11 & -0.46 & 0.08 & -0.31 & 0.06 & -0.30 & 0.06 \\
\hline \#3 & SiS & $\mathrm{Ga}$ & 6 & -0.76 & 0.28 & -0.61 & 0.20 & -0.41 & 0.17 & nd & \\
\hline \#3 & SiS & SSB & 6 & -0.75 & 0.28 & -0.63 & 0.20 & -0.63 & 0.17 & nd & \\
\hline \multicolumn{4}{|c|}{ "JMC" standard } & $\underline{-0.32}$ & $\underline{0.10}$ & $\underline{-0.23}$ & $\underline{0.12}$ & $\underline{-0.16}$ & $\underline{0.07}$ & $\underline{-0.16}$ & $\underline{0.05}$ \\
\hline \#1 & $\mathrm{HG}$ & SSB & 4 & -0.33 & $\overline{0.33}$ & $\overline{n d}$ & & -0.15 & $\overline{0.27}$ & -0.18 & $\overline{0.06}$ \\
\hline \#1 & $H G$ & $\mathrm{Ga}$ & 4 & -0.31 & 0.29 & nd & & -0.14 & 0.25 & -0.17 & 0.06 \\
\hline \#2 & SiS & SSB & 4 & -0.23 & 0.02 & -0.14 & 0.04 & -0.11 & 0.03 & -0.12 & 0.03 \\
\hline \#2 & SiS & DS & 4 & -0.32 & 0.07 & -0.24 & 0.05 & -0.16 & 0.04 & -0.16 & 0.04 \\
\hline \#3 & SiS & $\mathrm{Ga}$ & 8 & -0.37 & 0.04 & -0.25 & 0.02 & -0.19 & 0.07 & nd & \\
\hline \#3 & SiS & SSB & 8 & -0.37 & 0.16 & -0.28 & 0.14 & -0.20 & 0.06 & nd & \\
\hline \multicolumn{4}{|c|}{ "SPEX" standard } & $\underline{-0.71}$ & $\underline{0.21}$ & $\underline{-0.56}$ & $\underline{0.15}$ & -0.37 & $\underline{0.16}$ & $\underline{-0.31}$ & $\underline{0.08}$ \\
\hline$\# 1$ & $H G$ & SSB & 1 & -0.59 & nd & nd & & -0.28 & nd & -0.31 & nd \\
\hline$\# 1$ & $H G$ & $\mathrm{Ga}$ & 1 & -0.60 & nd & $n d$ & & -0.28 & nd & -0.31 & nd \\
\hline \#1 & $H G$ & SSB & 5 & -0.84 & 0.16 & $n d$ & & -0.48 & 0.10 & -0.36 & 0.08 \\
\hline \#1 & $H G$ & $\mathrm{Ga}$ & 5 & -0.81 & 0.11 & nd & & -0.46 & 0.09 & -0.35 & 0.04 \\
\hline \#2 & SiS & SSB & 3 & -0.61 & 0.04 & -0.51 & 0.09 & -0.33 & 0.03 & -0.28 & 0.05 \\
\hline \#2 & SiS & DS & 4 & -0.63 & 0.13 & -0.48 & 0.10 & -0.32 & 0.06 & -0.31 & 0.06 \\
\hline \#3 & SiS & $\mathrm{Ga}$ & 10 & -0.81 & 0.19 & -0.62 & 0.24 & -0.41 & 0.11 & nd & \\
\hline \#3 & SiS & SSB & 10 & -0.79 & 0.18 & -0.62 & 0.16 & -0.41 & 0.12 & $n d$ & \\
\hline \#4 & SiS & SSB & 14 & -0.64 & 0.42 & nd & & $n d$ & 0.00 & -0.23 & 0.26 \\
\hline \#4 & SiS & $\mathrm{Ga}$ & 14 & -0.79 & 0.18 & nd & & nd & 0.00 & -0.31 & 0.04 \\
\hline \multicolumn{4}{|c|}{ "ALDRICH" standard } & $\underline{-2.01}$ & $\underline{0.23}$ & -1.54 & $\underline{0.17}$ & $\underline{-1.03}$ & $\underline{0.12}$ & $\underline{-0.97}$ & $\underline{0.15}$ \\
\hline \#2 & SiS & SSB & 4 & -1.88 & 0.03 & -1.46 & 0.07 & -0.97 & $\overline{0.02}$ & -0.92 & 0.03 \\
\hline \#2 & SiS & DS & 4 & -2.14 & 0.06 & -1.61 & 0.05 & -1.08 & 0.03 & -1.05 & 0.03 \\
\hline \#2 & $\mathrm{HG}$ & DS & 6 & -1.90 & 0.10 & -1.44 & 0.08 & -0.96 & 0.05 & -0.94 & 0.05 \\
\hline \#3 & SiS & $\mathrm{Ga}$ & 84 & -2.08 & 0.26 & -1.61 & 0.20 & -1.08 & 0.16 & nd & \\
\hline \#3 & SiS & SSB & 84 & -2.05 & 0.22 & -1.60 & 0.20 & -1.06 & 0.14 & $n d$ & \\
\hline
\end{tabular}


Table 3:

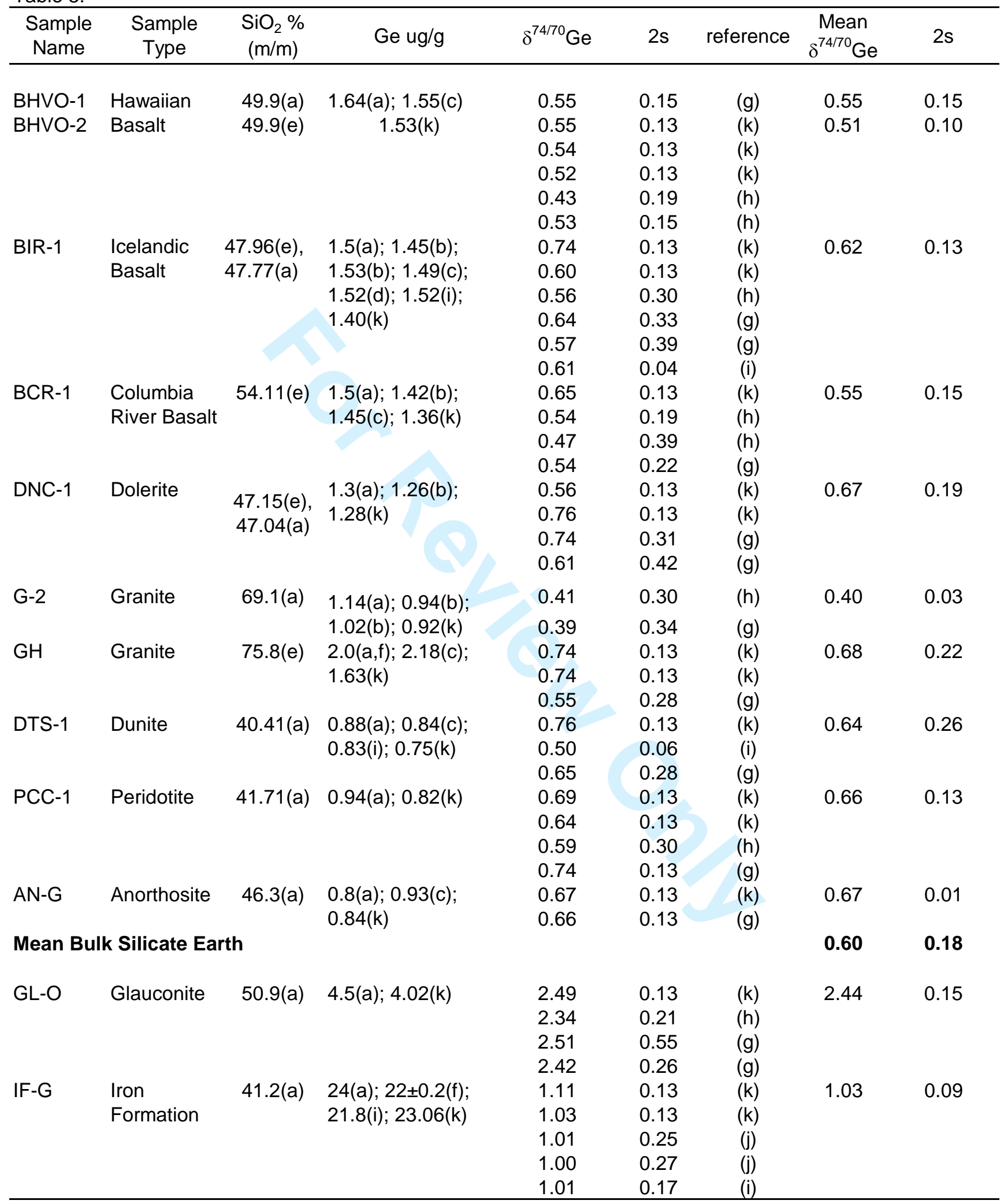


Table 4:

\begin{tabular}{lcccl}
\hline \multicolumn{1}{c}{ Sample Name } & $\mathrm{Ge} \mathrm{ug} / \mathrm{g}$ & $\delta^{74 / 70} \mathrm{Ge}$ & $2 \mathrm{~s}$ & source \\
\hline Iron meteorite & & & & \\
Odessa (IAB) & $288(\mathrm{a})$ & 0.96 & 0.07 & this study \\
& & 0.98 & 0.09 & Luais, 2007 \\
Braunau (IIA) & 183 & 1.47 & 0.24 & Luais, 2007 \\
Navan PbZn deposit & (b) & & & \\
U12473 & 12 & -3.86 & 0.25 & this study \\
U12474 & 12 & -3.95 & 0.22 & this study \\
U12487 & 4 & -3.36 & 0.27 & this study \\
U12487 & 6 & -2.82 & 0.28 & this study \\
U12499 & 28 & -4.28 & 0.14 & this study \\
Sphalerite (St Salvy mine, France) & & & \\
62W & 453 & -1.05 & 0.15 & Luais, 2007 \\
64W & 1047 & -2.06 & 0.15 & Luais, submitted \\
Seafloor sulfide deposits (c) & & & \\
FL-24-02 & 40 & -3.26 & 0.15 & this study \\
FL-19-08 & 45 & -3.24 & 0.16 & this study \\
ALV-2604-5-1A & 159 & -2.98 & 0.20 & this study \\
FL-18-03/fond & 200 & -4.00 & 0.11 & this study \\
\hline
\end{tabular}



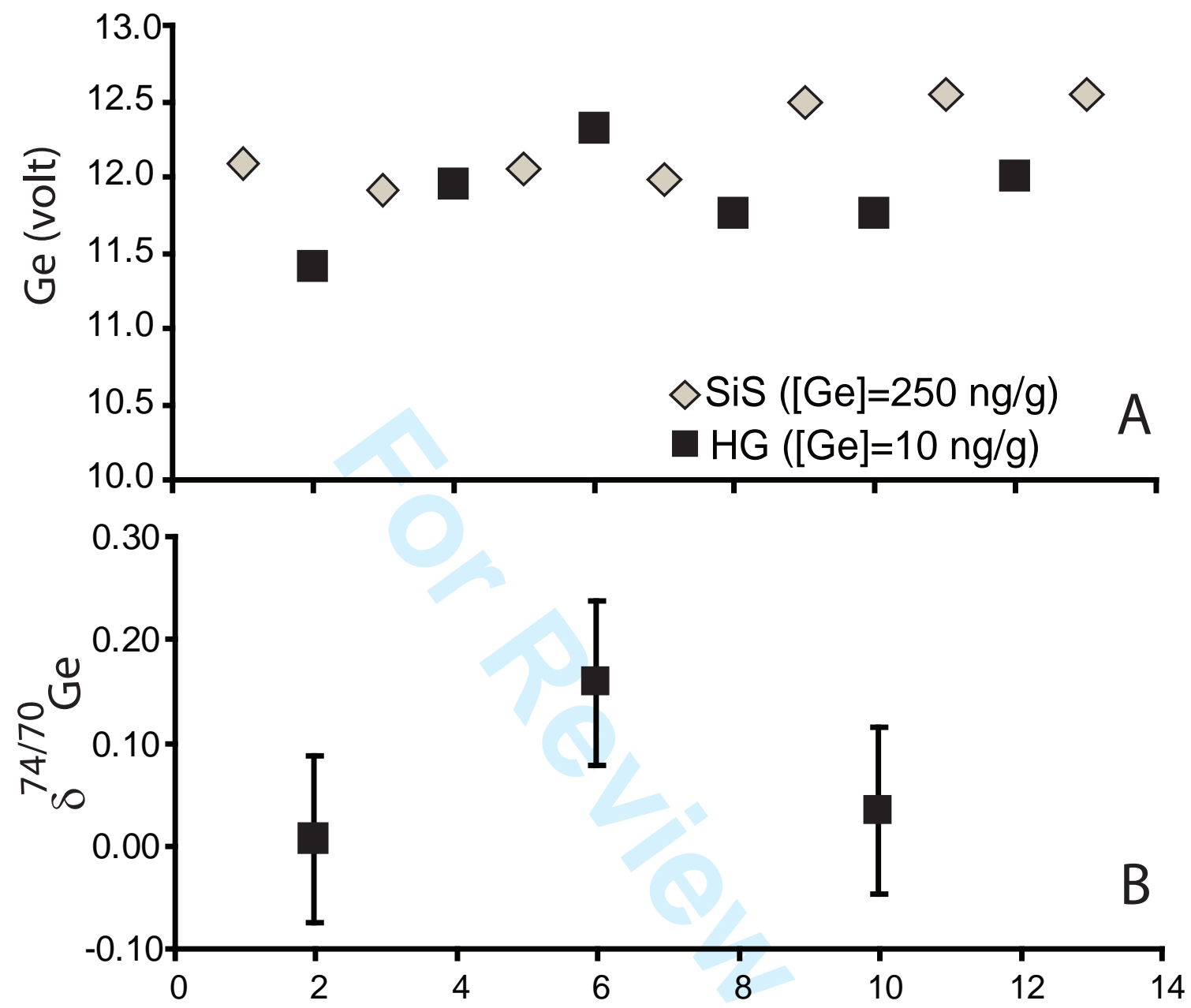

Analysis \#

Figure 1 


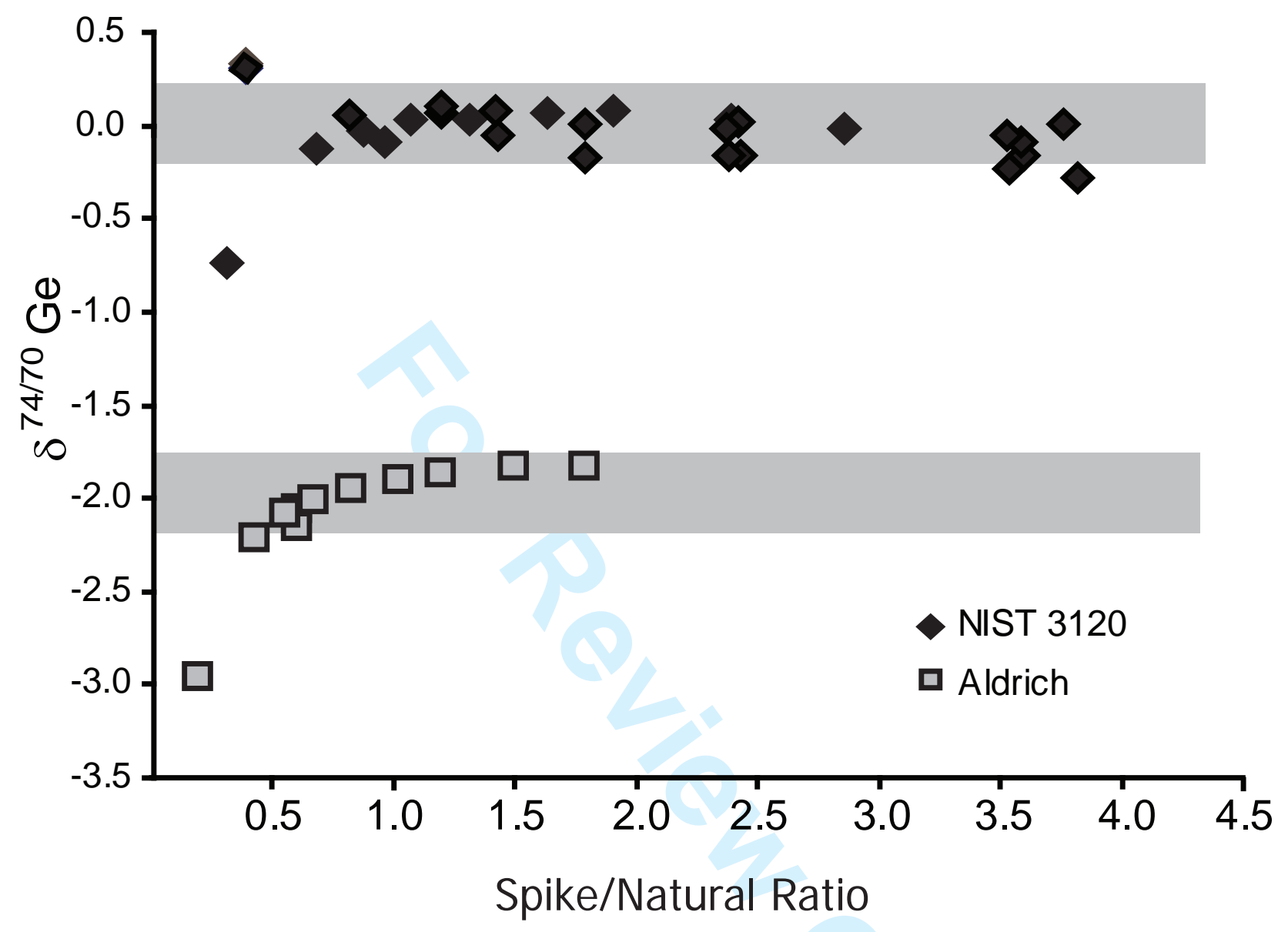

Figure 2 


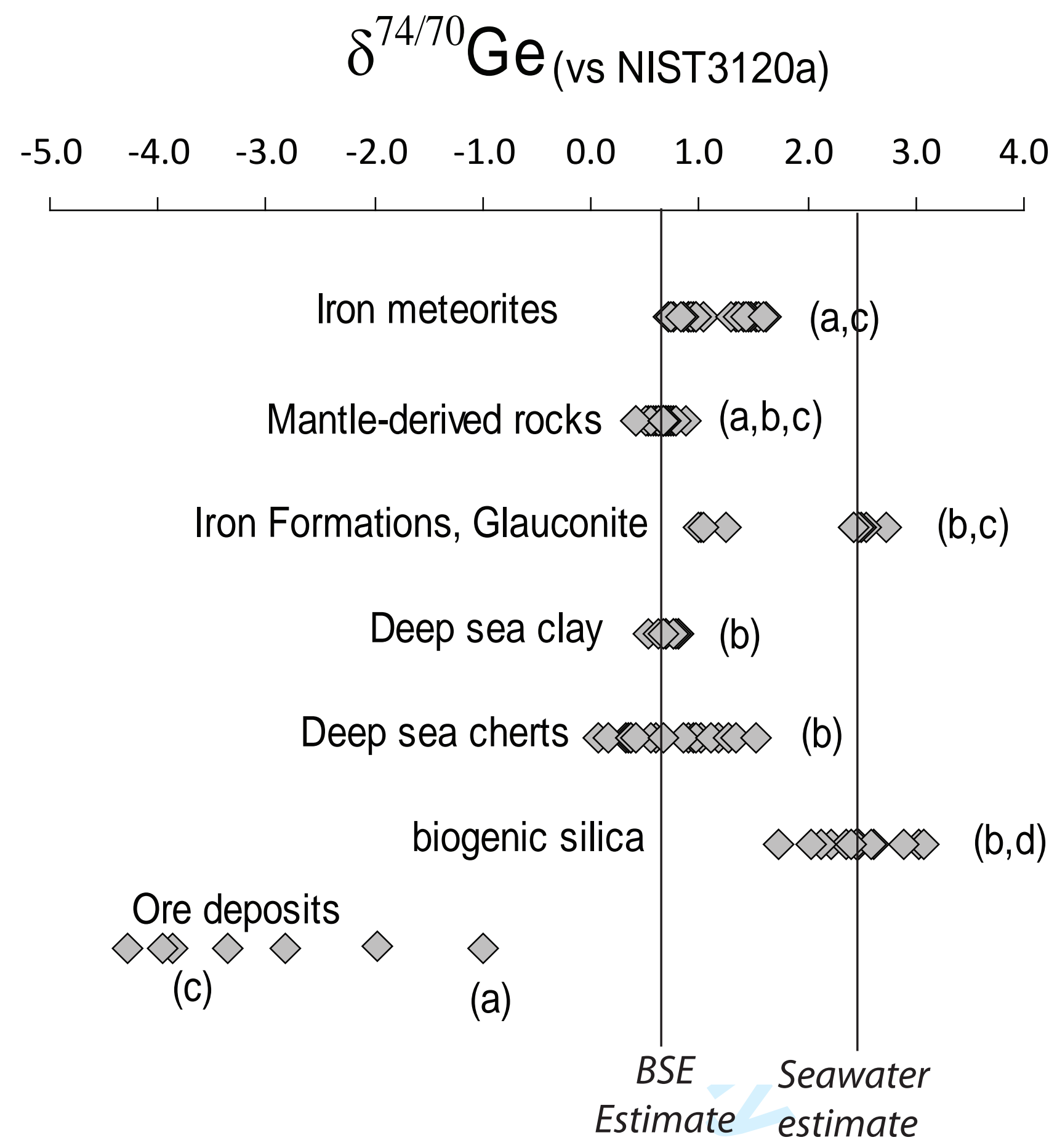

